\title{
BETWEEN CULTURAL AND COMMERCIAL OF NYONYA FOOD IN MELAKA
}

\author{
${ }^{1}$ Douglas Luebe \& ${ }^{2}$ Hanafi Hussin \\ *first author, $* *$ corresponding author \\ 1,2 Department of Southeast Asian Studies \\ Faculty of Arts and Social Sciences, \\ ${ }^{2}$ Institute of Ocean and Earth Sciences (IOES) \& \\ Social Advancement and Happiness Research Cluster, \\ University of Malaya, Kuala Lumpur \\ (hanafih@um.edu.my) \\ DOI: https://doi.org/10.22452/samudera.vol1no1.4
}

\begin{abstract}
This article explores the commodification of Nyonya food in Malacca. Nyonya cuisine gained recognition and became a commercialised cuisine over the past decades. A case study approach was used for this research to look into the emergence of these restaurants and their interaction with the heritage of the Baba Nyonya. Data regarding usage of food in the Baba Nyonya context was collected from secondary data, observations, informal interviews, and by eating at twenty Baba Nyonya restaurants. This information was used to provide a current overview of Baba Nyonya restaurants. From there, the analysis aims to identify examples and patterns of commodification resulting from the emergence of Nyonya restaurants. The effects of commodification are evaluated in terms of its influence on the forms and functions of Nyonya food. Forms of the food such as ingredients, menu items and preparation techniques show a wide range from remaining authentic to being highly commodified. In regard to function, the transition into the commercial sector as a means of earning wealth marks a deviation from the previous function of food as a key cultural aspect of celebrations and as an indication of wealth. Nonetheless, this transition of Nyonya food into the commercial sector marks a continuation of an even prior Baba Nyonya characteristic of business ingenuity and economic creativity.
\end{abstract}

Keywords: Baba Nyonya, Malacca, Commodification, Forms and Functions, Authenticity

\section{The Baba Nyonya}

The Baba Nyonya has been referred to as Peranakan, Straits Chinese, or Kings Chinese, but this article will use Baba Nyonya. The Baba Nyonya are descendants of Chinese traders who migrated and intermarried with the local population in Melaka. The exact timing of their arrival is unclear as Rudolph (1998) states that many of the earliest origin stories of the Baba Nyonya are "myths" and he estimates that their arrival dates 
to the early $17^{\text {th }}$ century. Others have listed the sixteenth century as the community's beginning (Lee, 2008) and others have indicated that it is even possible that the community originated "as early as the fifteenth century" (Stoddart, 2011). Regardless of their initial arrival, the height of their economic and social prominence was from the nineteenth to the early twentieth century (Stoddart, 2011). They were the primary intermediaries with the British traders and gained vast economic wealth. The Baba Nyonya community ranged from Penang to Malacca to Singapore and served as the intermediaries with the British traders.

Several factors led to the decline of the Baba Nyonya from their elite social status. One significant factor was the Great Depression, which impacted trade and prices such as a substantial decrease in the value of rubber. By the time of World War II, the Baba Nyonya community had declined, but it was the Japanese occupation that leads to an "almost certainly irreversible decline" of Baba culture, wealth, and status as they were targeted by the Japanese (Lee, 2008). After the war, the Baba Nyonya did not regain their privileged position as traders. Since then other factors have also contributed to the diminishment of Baba Nyonya identity; these factors include modernisation, social dispersion, marriage to non-Straits Chinese, and the changing role of the Nyonyas (Lee, 2008). Baba Malay, their creole language, is another core aspect of Baba Nyonya identity, which has diminished significantly in the past century. These factors have to lead to the overall "diminishing numbers of Peranakan today who actively observe or practice the culture" (Lee, 2008).

However, Baba Nyonya culture underwent a resurgence of interest, and by the end of the 1960s "persistent signs of a 'revival' could be observed" (Rudolph, 1998). The threat of a disappearing identity spurred the community into increased awareness and promotion of their heritage. The Baba Nyonya have been known for their adaptability and "acculturation" (Tan, 1997). In this regard, "Baba identities are sufficiently resilient to endure" (Henderson, 2003). Along with the resurgence in selfidentification, cultural tourism among the Baba Nyonya developed. The sale of Nyonya embroidery and Nyonya cuisine brought highlights of the glorious culture to a prominent place in Malaccan tourism. These economic ventures have continued to represent Baba Nyonya heritage to tourists.

\section{Tourism in Melaka}

The general rise of tourism in Melaka also contributed to the resurgence of interest in the Malaccan Baba Nyonya. Tourism of Melaka benefited from several government programs such as the formation of the Ministry of Tourism and Culture in the 1980s and the "Visit Malaysia" program in 1990, which highlighted cultural tourism. This contributed to tourism becoming "the most vibrant sector of Melaka's economy" (Worden, 2003). Another more recent boost resulted from the joint inscription of Penang and Melaka into UNESCO's World Heritage List in 2008 which lead to another "tremendous rise in tourist arrivals" (Rodzi et al., 2013).

The place of the Baba Nyonya was promoted in the city's tourism. They were "localised, nationalized, and Malayized Chinese and as such had a role to play in the heritage representations of Melaka (Worden, 2003). The syncretic aspects of their culture provided a means of highlighting Malaysia's diversity of cultures and a potential 
model for unity amid diversity for the developing nation. The Baba Nyonya also was a highlight of the diverse "history, culture, architecture, monuments, traditional art, and religious and ritual practice" across Malaysia (Othman \& Hamzah, 2013). Therefore the Baba Nyonya have a secure place in Malacca's tourism sector.

This provides opportunities for the Baba Nyonya to define and present their culture to the outside world, but there are also challenges with touristic representations. One critique of tourism is that it reanimates a culture that does not currently exist. This reanimation of the past can lead to "an exoticization of the Peranakan, and a freezing of their existence in a past time, which bears little relation to the present" (Rudolph, 1998). Although tourism increases the awareness of the Baba Nyonya, it does not mean that understanding of the community will result as the Baba Nyonya "may be one of the most talked-about communities in Malaysia, but it is also one of the most misunderstood" (Tan, 1988).

This rise in tourism and in particular, the food as an important tool for softpower strategy (Hussin, H, 2018), the Nyonya restaurants provides economic opportunities for the Baba Nyonya and highlights Nyonya cuisine. It is as an identifier of culture and history, but there is the potential for commodification to jeopardise cultural authenticity in this commercial context. Because of the possible benefits and issues of commodification in the rise of Nyonya restaurants, this study sought to examine how commodification for tourism has impacted Baba Nyonya cultural representations and the forms and functions of Nyonya cuisine.

\section{Commodification}

Often the term commodification leads to confusion as it is associated with Marx' commodification of labour, but the term is used in the literature to explain how cultural heritage is converted into a tourist product. An excellent overarching explanation of commodification is provided in the following:

"Commodification of culture for tourism occurs when a community's culture, developed over past years, perhaps centuries, and created through ordinary spontaneous evolution under principles of use-value ... becomes converted into objects of exchange value for tourist consumption" (George, 2010).

This prevalent view of commodification being intrinsically damaging to the minority people's culture and heritage is expressed in several other ways also. One description of commodification for tourism is that it is "a kind of institutionalised racism that celebrates primitiveness" (Mowforth \& Munt, 1998: 270). Another explanation of the concern is that commodification strips intrinsic cultural value to achieve economic value (Rodzi et al., 2013). "Consumer value culture" diminishes and minimises "the original culture" (George, 2010). Therefore, challenges between authenticity and tourism have stayed "at the heart of discussions about sociocultural consequences" in tourism for decades (Cole, 2007).

However, authenticity and commodification are not intrinsically "a dichotomous pair of concepts" (Xie, 2003). In the article "Beyond Authenticity and Commodification", Stroma Cole emphasises how the empowerment of the local 
community should be highlighted rather than just focusing on the notion of authenticity. One reason for this is that the relationship between authenticity and commodification "is a Western cultural notion" which can miss "the interface between power and culture" (Cole, 2007). Another point is that "the process of commodification does not necessarily destroy cultural products, for either the locals or the tourists" (Xie, 2003). Instead, commodification even can benefit a minority by highlighting the values of their culture and history (MacDonald, 1997). This article also follows the notion that commodification does not intrinsically contradict or diminish authenticity, but rather commodification is viewed in regards to the opportunities as well as the challenges it provides for an ethnic minority.

\section{Methodology}

A qualitative approach was used to do a case study of the Baba Nyonya in Malacca to investigate commodification in these restaurants. The study was mainly conducted by making observations and having informal interviews at twenty Nyonya restaurants. Of these restaurants, twelve were in Chinatown, and seven in Taman Melaka Raya and one was Donald \& Lily's Nyonya Cuisine which is just South of Chinatown. While at the restaurants, observations were made regarding appearance and ambience, food and drinks offered ingredients, preparation methods, etc. The interviews were mainly informal interviews lasting from five to thirty minutes at the restaurants to clarify observations or to ask about how the food is prepared and about the history of the restaurant. In June of 2014, there was a two-hour semi-structured interview at Donald \& Lily's with Donald Tan covering the history of the restaurant, authenticity, quality, menu items, and serving halal food. This was followed up with a second interview in September.

The Chinatown area of Malacca is the primary area of study for this research. Jonker Street is the famous road running through Chinatown, so the area is often referred to just as Jonker Street. The Chinatown area contains several other Baba Nyonya stores such as ones selling Nyonya beadwork, and art or Nyonya treats like pineapple tarts and cendol, so a range of Baba Nyonya products and culture have moved into the commercial sector. Baba Nyonya products for tourists go beyond restaurants, but the restaurants compose a large overall piece of the Baba Nyonya saleable goods for tourists.

\section{Nyonya Restaurants in Chinatown}

The restaurants showed a wide range of ambience. On one end of the spectrum, there is Restoran Peranakan, which presents a Baba Nyonya ambience through its art and scale. There were around 25 tables in the dining hall and large and intentionally spaced sculptures and mirrors. The restaurant presents as a reflection of the grandness and wealth of the former Baba Nyonya. To the contrary, Poh Piah Lwee is set up in a "hawker" style with three small stands alongside a few smaller tables in a small shop open to the outside air. This restaurant presents more of a small scale and family-style ambience. The other restaurants had an ambience in a range between these two restaurants with the majority giving more of a smaller and home-style feel. 
The menus at the restaurants varied in length between one to ten plus pages. Common menu items included laksa, rendang chicken, pongteh, asam fish, Buah keluak, and cendol. Egg, vegetable, and seafood options were also prevalent. One variation between the restaurants was whether there were non-Nyonya items on the menu. Three of the twelve restaurants had items that were distinctly non-Nyonya, such as at Café 1511, which had four pages of Western-style meals along with their Nyonya food options. The other nine restaurants did not have options like spaghetti or chicken fingers on their menu. Another variation between restaurants in the area is that eight of the twelve served halal food and four served non-halal food. Halal Nyonya cuisine differs from the traditional usage of pork in Nyonya food.

The ingredients and preparation of the dishes also differ between restaurants. An example of this is the variation in the spiciness of laksa from one store to another. Another example is the range in the flavour of pongteh. At several restaurants, the pongteh was halal and had a sweet flavour. At Tames Café Nyonya Cuisine, the owner explained how she makes hers without sugar, but with a thicker concentration of the original ingredients for the dish. The preparation at the restaurants showed some similarities across restaurants which differ from traditional methods. One example of this is the use of blenders to grind spices rather than hand grinding the ingredients. Another aspect of preparation that varies from the past is the ethnicity and gender of the cooks. Several of the restaurants employed international workers to prepare the food; sometimes, they were working alongside Baba Nyonya or Chinese cooks. At other restaurants such as Yeti Nyonya Delights, Poh Piah Lwee, and Tames Café Nyonya Cuisine the food was being prepared by Nyonyas. Many restaurants also had Chinese cooks. One interesting thing was that even when the cooks were international workers, the waiters were almost always of Chinese descent.

\section{The commodification of Forms in the Restaurants}

From this overview of Nyonya restaurants in Chinatown, the influence of commodification can be evaluated on the cuisine. This article will choose to distinguish between the commodification of the forms and the functions of Nyonya food. The form of the food encompasses tangible aspects such as the ingredients, flavour, preparation, presentation, etc. The function then is referring to the purpose or significance behind the food. Another explanation of this distinction is that the difference between form and function is that the function is the desired outcome of a tradition, and the form is the means of fulfilling that function. Because functions address the purpose and significance behind a tradition, changes in function represent a greater shift than a change in form. Therefore this analysis will begin with the commodification of forms of Nyonya food before progressing to the commodification of functions. Furthermore, these forms have been subdivided into the commodification of forms which can be observed objectively and then subjectively.

The first objective form of commodification is that the food is served in a restaurant. This commodification is self-evident and straightforward, but it differs from the past when Nyonya food was made in the home. Along these lines, the second commodification of form is that the food is mass-produced and ready to be ordered and served quickly. Nyonya meals were made in large quantities for parties in the past, so 
just having a lot of it is not necessarily a change. However, the daily preparation of large quantities and many types of dishes available throughout the day is a change necessitated to sustain a restaurant. Another obvious marker of commodification is that eight of the twelve restaurants served halal food. The Baba Nyonya followed traditional Chinese religion and therefore did not have the religious or cultural impetus to eat halal in the past, so homemade food was non-halal. That the majority of restaurants are now halal reveals that the food has been adapted to attract a wider consumer base. Another commodification is the extent to which the menu is Nyonya. This includes a minority of the restaurants, but that Nyonya food is being served alongside spaghetti, and other Western dishes reveals a change in what is made. These other dishes do not run the risk of being confused as Nyonya, but their incorporation on the menu again allows the "Nyonya" restaurant to appeal to a larger range of consumers. A fifth example of commodification was the ethnicity and gender of the cooks. This showed a range across stores as there were restaurants with Nyonya cooks, Chinese cooks, a combination of Chinese and foreign cooks, and just foreign cooks. This is a commodification from the original preparation of the food which was done by the Nyonyas.

There were also subjective commodifications of the forms of Nyonya cuisine. One is the range of formality and scale from home style to commercial style as in the difference between Restoran Peranakan and Poh Piah Lwee with other restaurants falling in between. The smaller stores cannot reproduce the extravagance of a Baba Nyonya party, but the home-cooked feel of a Nyonya meal can be presented there. However, on either end, these stores present a representation of a perceived past existence for the customer. Determining which representation is most historically accurate would be challenging to ascertain, but the different ambience and scale of the restaurants show how past culture has been reanimated to sell to the consumer. As many of the stores present a smaller homestyle and often a more quaint feel, these representations can support the notion of the "dichotomy between premodern (authentic) and modern (inauthentic)" in the tourist's perception.

A second subjective commodification of the food is in regards to authenticity. This is subjective in that there is a long history of Nyonya food and within any single period Nyonya cuisine and its recipes and preparation techniques varied across families, so it cannot be stated that there is a single "authentic" cuisine. Also, as previously discussed, the dichotomy between authentic and inauthentic will be unproductive here. While there is a large grey area regarding authenticity, some examples are more apparent, such as when curry mee is being sold as laksa. This is also subjective based on an individual's preference. Some of the elderly store owners described how they made their dishes authentically and expressed their concerns for the future of Nyonya cuisine as many of the younger generation they said are unable to differentiate between authentic and inauthentic food.

\section{Comparison of Taman Melaka Raya and Chinatown}

As a comparison point for commodification in Chinatown, seven Nyonya restaurants in Taman Melaka Raya (which is two kilometres away to the Southeast) were also studied. Originally the expectation was that the restaurants in each area would be mostly the same, but this is not what was observed. While the restaurants in the two areas have 
similarities and individual restaurants in either area may differ from these overall trends, systematic differences did emerge when comparing the two areas of study.

These differences showed up in both the objective and subjective commodification of forms. Firstly, all seven of the Nyonya restaurants in Taman Melaka Raya were halal compared to the four out of twelve non-halal restaurants in Chinatown. While several of the menus in Chinatown offered non-Nyonya options, all of the menus in Taman Melaka Raya were entirely Nyonya food. The next objective commodification distinction was in the ethnic diversity of the staff. Taman Melaka Raya restaurants had more ethnic diversity in the cooks and significantly more ethnic diversity among the waiters compared to almost all waiters in Chinatown being of Chinese descent. Regarding subjective distinctions, there were also systematic differences between the areas. The restaurants in Taman Melaka Raya were more consistently representative of the commercialised rather than the home-style restaurant. This was apparent in Taman Melaka Raya given the larger venues of the restaurants, the uniforms worn by employees, the closed-off kitchens, and the commonness of slogans (such as "a touch of Nyonya" or "27 years of good original Nyonya taste") at the restaurants. These differences of having larger venues, closed-off kitchens, more ethnic diversity, uniforms for the waiters and others reflect what would be common among typical restaurants. Thus it is interesting to note that these things are common in Taman Melaka Raya but less so in Chinatown.

Anyone of these disparities is not meant to offer conclusive evidence of commodification for a varied target audience, but cumulatively these disparities reveal commodification specific to the customer in each area. To understand the differences in each area, one ought to consider the target customer. Chinatown is heavily saturated with tourists whereas Taman Melaka Raya has a more local and Malay customer base. Interestingly then, the commodification of Nyonya cuisine does not just result from its entrance into the restaurant business, but it is also suited to the target audience. This supports Lowenthal's (2005) claim that touristic representations are formed to suit tourist expectations as the commodification of Nyonya food differs in the touristic Chinatown area.

\section{Identifying Changes of Functions}

The functions of Nyonya food also differs today from past functions. Historical functions of Nyonya cuisine include evaluating a bride, daily consumption, offering to ancestors, and displaying wealth at parties and festivals. Many of these functions continue today but to differing extents. Also, the changes to these functions of Nyonya food arose independently of restaurants. The role of cooking in evaluating a bride has changed as Nyonyas are more educated and autonomous. The food also played a diminished role in festivals and parties, and while home-cooked meals serve similar functions as before, they are not as typical or labour intensive as in the past.

Along with the changes in historical functions, new functions for Nyonya food have also come about with the rise of Nyonya restaurants. The primary function of Nyonya cuisine in restaurants is producing wealth and earning an income. This function is not a commodification of function resulting from the restaurant business, but rather the purpose of the restaurants started as earning a profit. After World War II, the Baba's 
diminished place in society resulted in other ventures in order to earn an income. Donald Tan from Donald \& Lily's claimed to be the first-ever Baba Hawker because foodservice was viewed as a more low-class job than befit the Baba Nyonya, but decades later the restaurant business has become a more conventional means of earning a living. A secondary function of Nyonya food is promoting and highlighting Baba Nyonya heritage and culture. This subsidiary function of Nyonya food serves to increase awareness and pride in Baba Nyonya culture and history. However sustaining the business remains primary as expressed by Donald Tan, who stated that "If our food is not good, no one will visit." Promoting Baba Nyonya legacy becomes a significant role of the food, but is contingent upon first succeeding in the function of sustaining the business.

\section{Changes in Chinese New Year Offerings}

As a reference point for observing the changes of Nyonya food in restaurants over the past decades, this study also examined changes in the traditional usage of Nyonya food. This was done by comparing Chinese New Year ancestral offerings from Tan Chee Beng's report in his 1979 doctoral thesis with observations, field notes made by Hanafi Hussin on January $24^{\text {th }} 2014$ and his published paper in JATI, 2014. Several similarities and changes were evident in the forms of the offering. Examples of continuity include maintaining the invitation system for welcoming the ancestors and the incorporation and worship of deities in the offering. Other similarities were the wide array of foods offered and the complexity of the dishes (figure1).

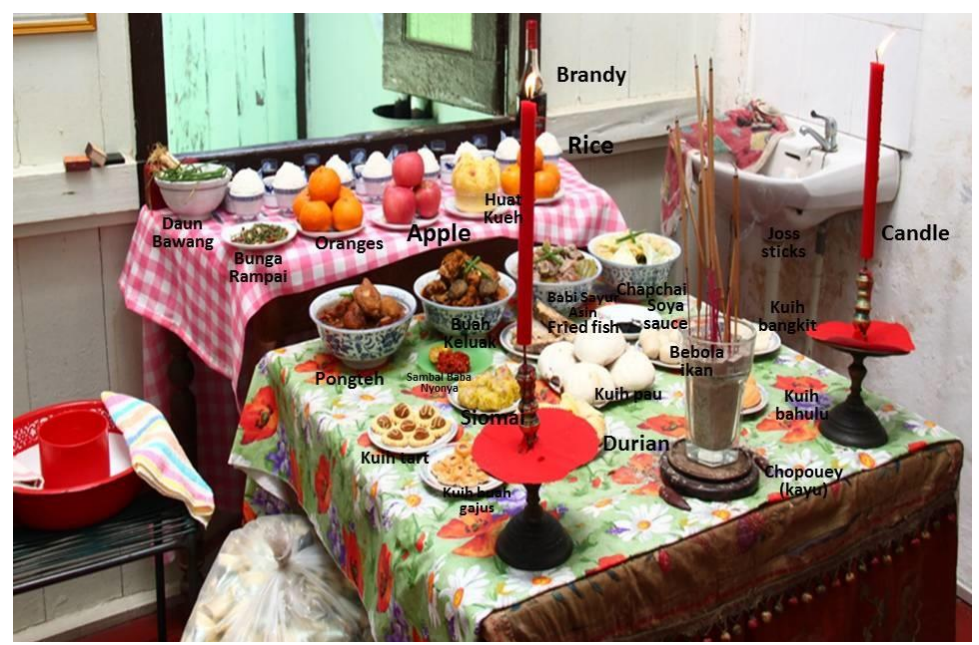

Figure 1: Food and drinks served for the ancestors and spirits of deceased family members at Madame Grace's ceremony

(Source: Hanafi Hussin, 2014)

The changes in the form represented an overall shift toward simplicity. One example of this is that the ceremony was a single two-hour ceremony rather than several offerings. Also, while the deities were honoured in Madam Grace's ceremony, there were more steps and greater overall incorporation of the deities in the ceremonies 
reported by Tan Chee Beng in 1979. While changes in form were evident, this comparison reveals continuity in the primary function of the offerings in that Madam Grace's purposes was to honour and satisfy her ancestors. Thus these observations follow Tan's assertion that "in the context of cultural change, it is generally easier for the form of an institution to change than its function" (Tan, 1979: 141).

The observations from the Nyonya restaurants showed a similar pattern as the forms of the food was commodified in the restaurants. The function of the food, on the other hand, changed to sustaining a business in order for the restaurants to begin and has since remained consistent with the additional function of promoting Baba Nyonya identity and heritage. This comparison of the Chinese New Year offerings also lends to the analysis of commodification in the Nyonya restaurant context by showing how changes in forms do arise independently of commodification. Therefore it is crucial to differentiate between changes resulting from general progression over time and changes resulting from the entrance into the commercial sector. Some of the commodifications of Nyonya food like using a blender are also reflected in contemporary Nyonya meals at home where it is increasingly uncommon for the spices to be hand ground. Nonetheless, the usage of a blender in the restaurants is still a change from traditional preparation techniques.

\section{Opportunities for the Baba Nyonya}

Commodification occurred as Nyonya food became a commercial product in addition to an aspect of Baba Nyonya cultural heritage. Increasing interest in the Baba Nyonya provided the opportunity to commercialize the cuisine. This entrance to the commercial sector reflects the current socioeconomic status of the Baba Nyonya but also highlights the desire to express Baba Nyonya culture and history. Thus these new functions are represented in the Nyonya restaurants and opportunities for the Baba Nyonya today. Commodification then has mainly impacted the forms of Nyonya cuisine, and the goals of the restaurant drove these changes (figure2).

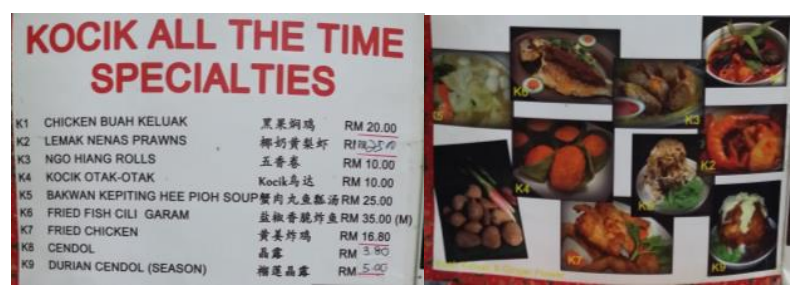

Figure 2: Commodification and its impact to Nyonya cuisine (source: fieldwork, 2014).

Therefore it can be stated that commodification is a subsidiary means of accomplishing commercial goals in the case of the Baba Nyonya. This may present challenges to the cultural heritage of the Baba Nyonya as restaurants may adapt their representations of the past to touristic expectations. However, if the secondary function of promoting Baba Nyonya heritage is also upheld, then the restaurants provide an opportunity for the Baba Nyonya to highlight their history to the outside world. The 
example of Donald \& Lily's represents this as the quality ingredients and authentic dishes and flavours are emphasized.

The high concentration of the Nyonya restaurants in Chinatown means that Nyonya restaurants will continue to play a significant role in touristic representations of the Baba Nyonya along with Nyonya artwork and Baba Nyonya museums in Chinatown. The range in extents of commodification between the Nyonya restaurants, including diversity in the menus, waiters, size and appearance of the restaurants, and other factors differs widely. Therefore the presentation of Baba Nyonya heritage will not be standardised. However, the Baba Nyonya could seek to promote specific restaurants or highlight the best of the Nyonya cuisine. This diversity in the restaurants may also be viewed as reflecting the diversity of the Baba Nyonya culture. Also, Nyonya cuisine is not limited to tourist areas as is evidenced by the expansion of the restaurants beyond the tourist demographic to the local audience outside of Chinatown. Therefore Nyonya restaurants can be a means of highlighting the unique minority's heritage in other areas as well.

\section{Conclusion}

Commodification changed the forms of Nyonya cuisine, but these changes stem from the change in the function of Nyonya cuisine which arose before commodification. Therefore commodification of the food is aimed to accomplish the new commercial function of the food. Opportunities to sell Nyonya food in restaurants did not require this change of a function. Rather this change in function developed because of the changing socioeconomic status of the Baba Nyonya. Then individuals in the Baba Nyonya community chose to enter the restaurant business. While this study revealed commodification, it also saw many Baba Nyonya who expressed their desire to highlight Baba Nyonya culture and history. Thus these restaurants can be a means by which the Baba Nyonya increase awareness of their identity for the world abroad and a means by which the Baba Nyonya take pride themselves. The diversity in their rich history and the culture, artwork, and cuisine of previous generations provide opportunities for the community to define and progress in their current identity.

Finally and interestingly, the craft and intricacy of Nyonya cuisine which originated resulting from Baba Nyonya wealth now serves the function of generating wealth and income. The socioeconomic status change for the Baba Nyonya leads to a revision and alteration of the function of food. In this regard, the commodification of Nyonya food is a continuation of the function of Baba ingenuity, adaptability and creativity in business.

\section{Acknowledgement}

This paper is an output of research funded by RP017D-13SBS (Ethnographic Study of Shared Traditional Food Heritage of Coastal Communities of the South China Sea and RU006F-2014 (Ocean Governance and Coastal Community Geopolitics \& Culture East Coast of Malaysia: Intangible Heritage Policy and Implementation. 


\section{References}

Cole, S. (2007). Beyond authenticity and commodification. Annals of Tourism Research, 34(4), 943-960.

George, E. W. (2010). Intangible cultural heritage, ownership, copyrights, and tourism. International Journal of Culture, Tourism and Hospitality Research, 4(4), 376-388.

Hussin, H. (2018). Gastronomy, Tourism and Soft Power of Malaysia. SAGE Open, October-December 2018: 1-11. DOI: https://doi.org/10.1177/2158244018809211

Hussin, H. (2014). Bridging the Past and Present through Food Heritage among Peranakan Chinese of the Straits of Malacca, JATI-Journal of Southeast Asian Studies, Vol.24(1), 219-231.

Henderson, J. (2003). Ethnic heritage as a tourist attraction: The Peranakans of Singapore. International Journal of Heritage Studies, 9(1), 27-44.

Lee, S. K. (2008). The Peranakan Baba Nyonya Culture: Resurgence or Disappearance? SARI, 26, 161-170.

Othman, R. N. R., \& Hamzah, A. (2013). Interdependency of Cultural Heritage Assets in the Old Quarter, Melaka Heritage City. Procedia-Social and Behavioral Sciences, 105, 577-588.

Rodzi, N. I. M., Zaki, S. A., \& Subli, S. M. H. S. (2013). Between Tourism and Intangible Cultural Heritage. Procedia-Social and Behavioral Sciences, 85, 411-420.

Rudolph, J. (1998). Reconstructing Collective Identities: The Babas of Singapore. Journal of Contemporary Asia, 28(2), 203-232.

Stoddart, B. (2011). Making a New Culture on the Indian Ocean Rim: the "Peranakan" in the Straits Settlements. The Great Circle, 7-21.

Tan, C. B. (1997). Chinese identities in Malaysia. Southeast Asian Journal of Social Science, 25(2), 103-116.

Worden, N. (2003). National identity and heritage tourism in Melaka. Indonesia and the Malay world, 31(89), 31-43.

Xie, Philip Feifan. (2003) The Bamboo-beating Dance in Hainan, China: Authenticity and Commodification, Journal of Sustainable Tourism, 11(1), 5-16.

Lowenthal, D. (2005) The Past is a Foreign Country. Cambridge and New York: Cambridge University Press.

MacDonald, S. (1997). A people's story: Heritage, identity and authenticity. Rojek, C. \& Urry, J. (eds.) Touring Cultures: Transformations of Travel and Theory, 155Á/175.

Mowforth, M., \& Munt, I. (1998). Tourism and sustainability: new tourism in the third world. Routledge, New York.

Tan, C. B. (1988). The Baba of Melaka: Culture and identity of a Chinese Peranakan community in Malaysia. Petaling Jaya, Malaysia: Pelanduk Publications.

Tan, C. B. (1979). Baba and Nyonya: a study of the ethnic identity of the Chinese Peranakan in Malacca. Cornell University.

\section{Interview}

Madame Grace, Bandar Hilir Melaka, February 2014.

Date Received: 15 September 2018 Date of Acceptance: 15 June 2019 